\title{
Sexual Activity and Risk of HIV Infection Among Patients With Schizophrenia
}

\author{
Francine Cournos, M.D., Jeannine R. Guido, M.A., Siobhan Coomaraswamy, M.D., \\ Heino Meyer-Bahlburg, Dr.Rer.Nat., Richard Sugden, M.A., and Ewald Horwath, M.D.
}

\begin{abstract}
Objective: This study sought to determine the frequency and types of sexual behavior among patients with schizophrenia and to assess the behavior with respect to risk of HIV infection. Method: Ninety-five inpatients and outpatients with a research diagnosis of schizophrenia underwent a series of face-to-face interviews to determine their sexual activity and correlate it with demographic characteristics, psychopathology, and medication side effects. Results: Forty-four percent of the patients had been sexually active in the preceding 6 months, and $62 \%$ of these had had multiple partners. Sexual activity was associated with greater general psychopathology. Having multiple sexual partners was associated with younger age, a lower level of functioning, the presence of delusions, and more positive symptoms. Of the sexually active patients, $12 \%$ reported at least one partner who was HIV positive or injected drugs, or both, and $50 \%$ had exchanged sex for money or goods. Ten percent of the patients had engaged in homosexual activity in the preceding 6 months and $22 \%$ during their lifetime; the frequency was similar among men and women. Consistent condom use was uncommon. Conclusions: $A$ substantial proportion of schizophrenic patients had recent histories of sexual abstinence, but an almost equal number were sexually active. Sexual activity was usually accompanied by behavior related to HIV risk. Sexual activity and having multiple partners were associated with certain measures of more severe illness. Younger patients were more likely to have multiple partners but were also more likely to use condoms. There is a need for aggressive prevention strategies with this population.
\end{abstract}

(Am J Psychiatry 1994; 151:228-232)

\begin{abstract}
The purpose of this study was to determine the frequency and types of sexual behavior among patients with the diagnosis of schizophrenia and to assess these behaviors from the perspective of risk of HIV infection. HIV seroprevalence has recently been estimated at $4.0 \%-8.9 \%$ among psychiatric inpatients in a variety of settings in New York City (1-4). Among the severely mentally ill, being black (2), use of injected drugs (1-4), (among men) a history of homosexual activity $(2,3)$, and (among women) a history of sex with a partner who uses injected drugs or one known to have HIV infection (3) have shown an association with seropositivity.
\end{abstract}

Received Jan. 6, 1993; revisions received April 22 and June 7, 1993; accepted June 22, 1993. From the New York State Psychiatric Institute and the Department of Psychiatry, College of Physicians and Surgeons, Columbia University, New York. Address reprint requests to Dr. Cournos, New York State Psychiatric Institute, Unit 112, 722 West 168th St., New York, NY 10032.

Supported by NIMH grant MH-46251 and the New York State Office of Mental Health.

The authors thank Karen McKinnon, Ezra Susser, Ilan Meyer, Maureen Empfield, Brenda Agosin, Louis Caraballo, Elizabeth Margoshes, and Diane Engel for their help.

Copyright (O) 1994 American Psychiatric Association.
Many reports have associated psychiatric diagnoses with specific sexual behaviors, for example, mania and organic brain syndrome with hypersexuality $(5,6)$ and borderline personality disorder with multiple sexual partners $(7,8)$. It has been suggested that individuals with schizophrenia have an initial increase in sexual activity which lessens over the course of the illness, frequently to marked hyposexuality (9). Homosexuality among men with schizophrenia has received much more study and comment than homosexuality among women with this diagnosis $(10,11)$, and homosexual behavior has been reported to occur with greater frequency among these men $(9,12)$, especially in institutional settings (13). Comorbid substance use may accompany any psychiatric disorder (14), possibly increasing risky sexual behavior. However, the links between diagnosis and sexual behavior are poorly understood and in need of empirical study.

On the basis of the studies we have cited and additional literature on both mental illness and sexuality, we hypothesized that among patients with schizophrenia 1) a substantial number would be sexually abstinent, 2 ) younger patients would be more sexually active than older patients, 3 ) reports of homosexual activity 
would be more prevalent among men than among women, 4) positive symptoms would correlate with being more sexually active and negative symptoms with being less sexually active, and 5) reports of sexual side effects from psychotropic medication would be associated with sexual abstinence. Previous studies in this area have reported diagnostic data from unstructured clinical interviews and data on sexual behavior from instruments without proven reliability. In this study, research diagnoses were established, and a tested sexual behavior interview was used to investigate our hypotheses.

\section{METHOD}

Subjects were recruited from four New York City sites serving patients with severe and persistent mental illness. Two sites, a day treatment program and an acute inpatient unit, were located at an academic medical center in northern Manhattan. The other two sites were at a state hospital in Queens: an inpatient unit for homeless, mentally ill street people and a ward that prepares people for community living. With the exception of a small number of patients on the homeless unit, all patients had had the opportunity for sexual activity and drug use off the hospital grounds within the preceding 6 months.

Clinicians were asked to refer all patients between the ages of 18 and 59 years who, in their judgment, had the capacity to consent to research. A member of the research team then approached each referred patient. Of the 264 patients referred, 200 consented to be interviewed, 61 refused, and three dropped out of the study after consenting. This resulted in an overall acceptance rate of $76 \%$.

Of the 200 consenting patients, 95 had a primary diagnosis of schizophrenia established by the Structured Clinical Interview for DSM-III-R (SCID) (15). These patients underwent extensive face-toface sexual behavior interviews by trained research staff members using the Sexual Risk Behavior Assessment Schedule (Meyer-Bahlburg et al., 1990). This instrument, developed for injected-drug users and adapted for a psychiatric population, elicits detailed verbal reports of sexual activity. Item order, exploration of patients' sexual vocabulary, and interviewers' explicit definitions of sexual practices are designed to put patients at ease in talking about sex. The reinterview reliability of selected variables from the Sexual Risk Behavior Assessment Schedule was found to be high in this group $(0.60-0.89)(16)$. In this article, the terms "sexual activity" and "sexual episodes" are defined as oral sex or anal or vaginal intercourse with a partner. "Current" sexual activity refers to the preceding 6 months.

Patients' symptoms were evaluated with the Positive and Negative Syndrome Scale (17). This instrument also includes a general psychopathology scale, which is a separate but parallel measure of severity of schizophrenic illness $(17,18)$. Overall level of functioning was assessed with the Global Assessment of Functioning scale (15), which ranges from 0 (persistent danger to self or others) to 90 (absent or minimal symptoms). Patients were also asked questions about the effects of their psychiatric medications.

Data analysis consisted of group comparisons (two-tailed $t$ test or chi-square test) and correlations; both standard parametric and nonparametric statistical methods were used. Nonparametric statistical methods (rank transformations) (19) were used when measurement scales deviated from parametric conditions. This was the case for certain variables that included number of sexual partners and number of sexual episodes, both of which had asymmetrical distributions.

\section{RESULTS}

Table 1 presents sociodemographic and clinical information on the overall group of 95 patients with schizophrenia. The mean age of the patients was 36 years $(\mathrm{SD}=8.3)$. The mean number of hospitalizations was
TABLE 1. Demographic and Clinical Data on 95 Schizophrenic Patients

\begin{tabular}{|c|c|c|}
\hline Item & $\mathbf{N}$ & $\%$ \\
\hline \multicolumn{3}{|l|}{ Treatment site } \\
\hline Day treatment program & 44 & 46 \\
\hline Community preparation ward & 25 & 26 \\
\hline Homeless unit & 20 & 21 \\
\hline Acute inpatient unit & 6 & 6 \\
\hline \multicolumn{3}{|l|}{ Age } \\
\hline $18-39$ years & 60 & 63 \\
\hline $40-59$ years & 35 & 37 \\
\hline \multicolumn{3}{|l|}{ Gender } \\
\hline Male & 70 & 74 \\
\hline Female & 25 & 26 \\
\hline \multicolumn{3}{|l|}{ Race/ethnicity } \\
\hline Black, non-Hispanic & 44 & 46 \\
\hline Hispanic & 31 & 33 \\
\hline White, non-Hispanic & 19 & 20 \\
\hline Asian & 1 & 1 \\
\hline \multicolumn{3}{|l|}{ Level of education ${ }^{2}$} \\
\hline Less than high school graduation & 49 & 53 \\
\hline High school graduation or more & 44 & 47 \\
\hline \multicolumn{3}{|l|}{ Marital status ${ }^{2}$} \\
\hline Not married & 70 & 74 \\
\hline Ever married & 24 & 26 \\
\hline \multicolumn{3}{|l|}{ Previous psychiatric hospitalizations ${ }^{2}$} \\
\hline 0 & 6 & 6 \\
\hline 1 & 14 & 15 \\
\hline 2 or more & 74 & 79 \\
\hline \multicolumn{3}{|l|}{ Charted substance abuse history ${ }^{a}$} \\
\hline Yes & 62 & 67 \\
\hline No & 30 & 33 \\
\hline \multicolumn{3}{|c|}{ Sexually active during preceding 6 months } \\
\hline Yes & 42 & 44 \\
\hline No & 53 & 56 \\
\hline
\end{tabular}

${ }^{2} \mathrm{~N}$ differs slightly for this variable because of missing information on some patients.

$5.6(\mathrm{SD}=10.6)$, and the mean Global Assessment of Functioning score was 36.9 ( $\mathrm{SD}=6.5$, range $=15-51$ ), reflecting a predominantly chronically ill population. Male and female patients did not differ in general psychopathology according to the general psychopathology scale of the Positive and Negative Syndrome Scale; however, the men had significantly more negative symptoms than the women $(t=2.25, d f=90, p=0.03)$.

\section{Sexually Active Patients Versus Abstinent Patients}

Of the 95 schizophrenic patients, $42(44 \%)$ were sexually active: $29(41 \%)$ of 70 men and $13(52 \%)$ of 25 women. There was no significant association between sexual activity and age, gender, race/ethnicity, or level of education. A trend for outpatients to be more sexually active than inpatients did not reach statistical significance $\left(\chi^{2}=3.6, d f=1, p=0.07\right)$. Sexually active patients had greater general psychopathology as measured by the general psychopathology scale of the Positive and Negative Syndrome Scale $(t=-3.13$, df $=$ $91, p=0.002$ ); however, there were no differences between the sexually active and the abstinent patients in overall level of functioning, in scores on the positive and negative symptom scales, or in number of previous hospitalizations. 
FIGURE 1. Sexual Activity of 42 Sexually Active Schizophrenic Patients During the Preceding 6 Months

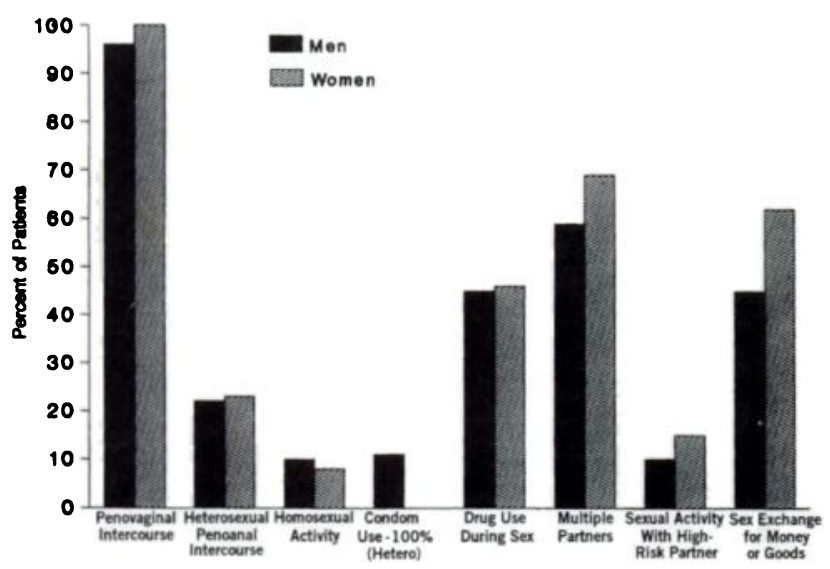

Monogamous Patients Versus Patients With Multiple Partners

Sixteen (38\%) of 42 sexually active subjects reported monogamous behavior. For these 16 patients, the mean number of sexual episodes was 29.4 ( $S D=47.9$, median $=8$, range $=1-180$ ). For the 26 sexually active subjects with multiple sexual partners $(62 \%)$, the mean number of sexual episodes was 34.3 ( $\mathrm{SD}=52.2$, median $=9.5$, range $=2-218$ ). Those who currently had multiple sexual partners were younger than those who had one sexual partner $(t=3.44, d f=40, p=0.001)$.

Since age and having multiple sexual partners were found to be highly correlated, the effects of age were controlled for when we examined the correlation between multiple sexual partners and other dependent variables. Gender, race/ethnicity, level of education, general psychopathology, and negative symptoms were not associated with having multiple sexual partners in partial correlations controlled for age. The patients who had multiple partners had a lower level of overall functioning $(r=0.30, N=39, p=0.05)$, significantly more positive symptoms $(r=-0.46, \mathrm{~N}=38, \mathrm{p}=0.003)$, and a greater likelihood of having delusions $(r=-0.36, N=38$, $\mathrm{p}=0.02$ ) than the monogamous patients.

\section{Current Sexual Risk Behavior}

Figure 1 contains information by gender on the sexual activity of all of the sexually active patients during the preceding 6 months. In addition, we used rank-transformed variables to compare men and women with multiple partners on number of partners and number of episodes and found no significant differences in either. Men had a median of two partners and 10 episodes, and women had a median of three partners and nine episodes. For men, the mean number of partners was $4.2(\mathrm{SD}=5.4$, range $=$ 2-24); for women, the mean number of partners was 19.1 ( $S D=47.6$, range $=2-146$ ) (comparison of rank means: $t=$ $-0.60, \mathrm{df}=24, \mathrm{p}=0.55$ ). For men, the mean number of episodes was $27.0(\mathrm{SD}=5.4$, range $=2-122)$; for women, the mean was 48.0 episodes $(\mathrm{SD}=74.7$, range $=2-218)$ (comparison of rank means: $\mathrm{t}=-0.67, \mathrm{df}=24, \mathrm{p}=0.51)$.

Homosexual activity was reported by four $(10 \%)$ of 42 patients, three men and one woman. Of these, only one male patient was currently engaging exclusively in same-sex activity.

Consistent condom use among the sexually active patients was uncommon, with only $8 \%(\mathrm{~N}=3$ of 40$)$ of the subjects reporting $100 \%$ condom use during vaginal or heterosexual anal intercourse. Men and women did not differ significantly in their reports of frequency of condom use $\left(\chi^{2}=1.01, \mathrm{df}=1, \mathrm{p}=0.31\right)$. The individuals who did not use condoms were significantly older than those who used condoms $(t=2.01, d f=38, p=0.05)$. Examining the association between condom use and number of partners, we found that $13(50 \%)$ of the 26 patients with multiple partners and $10(71 \%)$ of 14 patients with one sexual partner reported never using condoms. This difference was not significant $\left(\chi^{2}=1.71, \mathrm{df}=1, \mathrm{p}=0.19\right)$.

Among the $45 \%(\mathrm{~N}=19)$ of the patients who reported using drugs or alcohol during sex, alcohol was the most commonly used substance. Those using crack cocaine during sex (three, $7 \%$, of 42 patients) were women.

Five $(12 \%)$ of the 42 sexually active patients reported having sex with a partner known to be an injected-drug user. Of these five, all had multiple sexual partners; one reported never using a condom, while four reported inconsistent condom use. In addition, three of these five individuals reported having sex with partners who had other known risk factors. One man and one woman had sex with partners who were known to have HIV infection or AIDS, and one female patient had male partners who were bisexual and partners who had had blood transfusions between 1977 and 1985 .

We also examined sex exchange behavior (sex bought or sold for money, drugs, or goods such as food or rent) in our sexually active group. We found that $50 \%$ $(\mathrm{N}=21)$ of these patients participated in sex exchange. Overall, men and women did not differ significantly in whether they engaged in this behavior $\left(\chi^{2}=1.0, \mathrm{df}=\right.$ $1, p=0.32$ ). However, when we evaluated buying sex and selling sex separately by gender, a clear pattern emerged: men were more likely to buy sex, and women were more likely to sell sex. Nine men bought sex, two sold sex, and two did both. Seven women sold sex, and one woman both bought and sold sex. Sex exchange behavior was associated with having multiple partners. Seventeen $(81 \%)$ of the 21 patients who participated in sex exchange had multiple partners, while nine $(43 \%)$ of the 21 patients who reported no sex exchange had multiple partners $\left(\chi^{2}=4.9, \mathrm{df}=1, \mathrm{p}=0.03\right.$, with Yates's correction). Half of the patients who exchanged sex for money or goods reported never using condoms. One female patient involved in sex exchange also reported being forced into having sex.

\section{Lifetime Homosexual Activity}

To better clarify the issue of homosexual activity among individuals with schizophrenia, we examined 
lifetime histories of this behavior among the 94 patients for whom this information was available. Twenty-one $(22 \%)$ of the 94 patients $(16,23 \%$, of 69 men, and five, $20 \%$, of 25 women) reported homosexual activity prior to the immediately preceding 6 months. All 21 of these patients had engaged in past heterosexual behavior as well. Ten $(48 \%)$ of these 21 individuals reported no current sexual activity of any kind. It is interesting to note that none of these patients identified themselves as homosexual.

\section{Sexual Side Effects of Psychotropic Medication}

There was no significant association between sexual activity and route of medication (intramuscular versus oral) or sexual side effects due to medication. Subjective reports of sexual side effects were twice as high among the sexually active subjects as among the abstinent subjects, although the difference did not reach statistical significance.

\section{DISCUSSION}

Our hypothesis that a substantial proportion of patients with schizophrenia would be sexually abstinent was supported. However, nearly half of the patients had been sexually active in the preceding 6 months, and sexual activity was almost always accompanied by HIV risk behavior. Numbers of sexual partners and episodes were highly variable, reflected in large differences between the means and the medians for these variables, especially for women. Greater general psychopathology was associated with being sexually active.

Our findings did not support our hypotheses that older age, more negative symptoms, and the presence of medication side effects would be associated with sexual abstinence. None of these factors differentiated sexually active patients from abstinent patients, nor did gender, race/ ethnicity, level of education, number of previous hospitalizations, or level of functioning. Although age was not correlated with current sexual activity, younger age, more positive symptoms, presence of delusions, and a lower level of functioning were associated with having multiple sexual partners rather than being monogamous. Both current sexual activity and having multiple partners were therefore associated with certain measures of more severe illness. This suggests that clinicians should carefully evaluate and address HIV risk-related behavior among severely ill patients.

Although our study does not permit a detailed understanding of the impact of psychotropic drugs on sexual behavior, it appears that for many patients, the sexual side effects of medication are by no means an absolute barrier to sexual activity. It may be that sexually active patients are more likely to notice sexual side effects but that our study group was too small to demonstrate this. In addition, almost all of the sexually active men with side effects reported engaging in activities that require the ability to achieve erection, namely, vaginal inter- course, heterosexual anal intercourse, or both. Since patients taking intramuscular medication are more likely to receive the full dose than patients taking oral medication (who have greater opportunities for noncompliance with medication regimens), it is also notable that the route of administration of medication did not correlate with the presence of sexual activity.

Most patients who were sexually active engaged in behavior that put them at risk for HIV infection: $93 \%$ used condoms intermittently or not at all during vaginal or heterosexual anal intercourse, $62 \%$ had multiple sexual partners, $50 \%$ participated in sex exchange, and $12 \%$ had risky partners. In addition, $45 \%$ of the sexually active patients used drugs or alcohol during sex, which may affect risk-taking behavior. Condom use was greater among younger patients but did not differ between men and women or between patients with one sexual partner and those with multiple partners.

Our hypothesis that men with schizophrenia would have higher rates of homosexual behavior than women with this diagnosis was not supported. This study reveals a complex but comparable picture of homosexual behavior among men and among women. A substantial minority of both groups reported present or past homosexual activity, the majority identified themselves as heterosexual, and all reported current or past heterosexual activity. Our patients with schizophrenia engaged in homosexual activity intermittently. Future research should investigate the association of this behavior with phase of illness and institutionalization in same-sex settings. Asking patients whether they consider themselves straight or gay seems unlikely to provide accurate information about their homosexual behavior.

Our study found types of HIV risk behavior similar to those reported by Kelly et al. (20) in a study of 60 chronically mentally ill outpatients of mixed diagnoses. However, in comparison to that study, we found higher rates of certain risk behaviors, including multiple partners among the women and sex exchange.

The limitations of our study include a possible selection bias created by the exclusion of patients who lacked the capacity to consent and by the $24 \%$ rate of refusal or dropout. We do not know which of the nonparticipating patients would have met the SCID criteria for the diagnosis of schizophrenia, and therefore we cannot meaningfully compare them with the participating patients. Since incapable or refusing patients may have greater psychopathology, they could also be engaging in greater HIV risk behavior.

The majority of our patients were chronically ill, and these findings may not be applicable to more acutely ill patients. Patterns of risk behavior may also vary with geographic region. Other limitations include the small subgroup sizes, especially that of the sexually active women, and the use of self-reports on compliance with medication regimens.

In summary, most of the sexually active patients with schizophrenia were exposing themselves to the risk of acquiring, or possibly transmitting, HIV infection. These findings underscore the necessity for clinicians to 
improve detection of HIV risk behaviors and to implement risk-reduction programs.

\section{REFERENCES}

1. Sacks M, Dermatis H, Looser-Ott S, Burton W, Perry S: Undetected HIV infection among acutely ill psychiatric inpatients. Am J Psychiatry 1992; 149:544-545

2. Cournos F, Empfield M, Horwath E, McKinnon K, Meyer I, Schrage H, Currie C, Agosin B: HIV seroprevalence among patients admitted to two psychiatric hospitals. Am J Psychiatry $1991 ; 148: 1225-1230$

3. Volavka J, Convit A, Czobor P, Douyon R, O'Donnell J, Ventura F: HIV seroprevalence and risk behaviors in psychiatric inpatients. Psychiatry Res 1991; 39:109-114

4. Meyer I, McKinnon K, Cournos F, Empfield M, Bavli S, Engel D, Weinstock A: HIV seroprevalence among long-stay patients in a state psychiatric hospital. Hosp Community Psychiatry 1993; 44:282-284

5. Gewirtz G, Horwath E, Cournos F, Empfield M: Patients at risk for HIV (letter). Hosp Community Psychiatry 1988; 39:13111312

6. Miller BL, Cummings JL, McIntyre H, Ebers G: Hypersexuality or altered sexual preference following brain injury. J Neurol Neurosurg Psychiatry 1986; 49:867-873

7. Stein M: The treatment of a female low-level borderline personality disorder. Issues in Ego Psychol 1990; 13(2):124-139

8. Farrugia DL: Recognizing emerging borderline personality disorders. School Counselor 1992; 39(3):195-201

9. Akhtar S, Thomson JA: Schizophrenia and sexuality: a review and a report of twelve unusual cases, part II. J Clin Psychiatry $1980 ; 41: 166-174$
10. Freud S: Psychoanalytic notes on an autobiographical account of a case of paranoia (1925), in Collected Papers, vol III. Edited by Jones E; translated by Riviere J. London, Hogarth Press, 1950

11. Klein HR, Horwitz WA: Psychosexual factors in the paranoid phenomena. Am J Psychiatry 1949; 105:697-701

12. Lukianowicz $\mathrm{N}$ : Sexual drive and its gratification in schizophrenia. Int J Soc Psychiatry 1963; 9:250-258

13. Klaf FS, Davis CA: Homosexuality and paranoid schizophrenia: a survey of 150 cases and controls. Am J Psychiatry 1960; 116: 1070-1075

14. Anthony JC, Helzer JE: Syndromes of drug abuse and dependence, in Psychiatric Disorders in America. Edited by Robins LN, Regier DA. New York, Free Press, 1991

15. Spitzer RL, Williams JBW, Gibbon M, First MB: Structured Clinical Interview for DSM-III-R-Patient Version (SCID-P). New York, New York State Psychiatric Institute, Biometrics Research, 1989

16. McKinnon K, Cournos F, Meyer-Bahlburg HFL, Guido J, Caraballo LR, Margoshes ES, Herman R, Gruen RS, Exner TM: Reliability of sexual risk behavior interviews with psychiatric patients. Am J Psychiatry 1993; 150:972-974

17. Kay SR, Opler LA, Fiszbein A: The Positive and Negative Syndrome Scale (PANSS) Rating Manual. Toronto, Multi Health Systems, 1990

18. Kay SR, Fiszbein A, Opler LA: The Positive and Negative Syndrome Scale (PANSS) for schizophrenia. Schizophr Bull 1987; $13: 261-276$

19. Conover WJ, Iman RL: Rank transformations as a bridge between parametric and nonparametric statistics. Am Statistician 1981; 35(3): 124-129

20. Kelly JA, Murphy DA, Bahr GR, Brasfield TL, Davis DR, Hauth AC, Morgan MG, Stevenson LY, Eilers MK: AIDS/HIV risk behavior among the chronic mentally ill. Am J Psychiatry 1992; 149:886-889 